\title{
Guerra, historia, turismo y prensa: bases de la puesta en valor del patrimonio cultural de Niebla (Huelva) durante el franquismo
}

\author{
Enrique INFANTE LIMÓN \\ Diploma de Estudios Avanzados en Historia del Arte. \\ enriqueinfantelimon@gmail.com
}

Recibido: 12 de junio de 2014

Aceptado: 7 de octubre de 2014

\section{Resumen:}

Durante los años de la dictadura franquista se produjo un fenómeno de valorización del patrimonio cultural de Niebla, vinculado con ciertos valores promovidos por el régimen, como todos aquellos relacionados con la historia bélica.

Palabras clave: Patrimonio Cultural; Historia; Guerra; Turismo; Prensa; Recinto Fortificado.

\section{War, history, tourism and press: placing a value on the Cultural Heritage of Niebla (Huelva) during the Franco's dictatorship}

\begin{abstract}
During the years of the Franco's dictatorship there was an enhancement of Cultural Heritage of Niebla, related to some values promoted by the regime, such as those regarding the history of warfare.
\end{abstract}

Key words: Cultural Heritage; History; War; Tourism; Press; Fortified Wall.

\section{Referencia normalizada}

Infante Limón, E. (2014) Guerra, Historia, turismo y prensa: bases de la puesta en valor del patrimonio cultural de Niebla (Huelva) durante el franquismo. Historia y Comunicación Social. Vol. 19. Páginas 153-170.

Sumario: 1. Introducción. 2. La importancia de la Historia en la legitimación del franquismo. 3. Niebla y su historia durante el régimen. 4. El turismo como motor de desarrollo y el creciente interés de Niebla. 5. Primeros beneficios y mayor compromiso con la actividad turística. 6. Conclusiones. 7. Referencias bibliográficas. 


\section{Introducción}

Podemos decir que el conjunto de interesantes bienes patrimoniales que alberga la localidad onubense de Niebla -la muralla de tapial de época almohade, el templo bajomedieval de Santa María de la Granada, que reaprovechó una antigua mezquita, el Alcázar de los Guzmanes o la cabecera gótica de la antigua parroquial de San Martín-, se antoja incluso escaso para el rico bagaje histórico y cultural de una población cuyo origen se remonta a los comienzos del primer milenio a. C. Tal es la importancia de la población para la Historia del extremo suroeste peninsular, que la Universidad de Huelva, en 1993, puso en marcha un proyecto sistemático de arqueología urbana (Campos; Rodrigo; Gómez, 1996) que ha venido a arrojar nueva luz sobre el papel que jugó en determinados momentos del pasado y a poner al día todo lo relacionado con la ciudad histórica (Campos; Gómez; Pérez, 2006).

Hoy, como consecuencia de una serie de trabajos conducentes a la obtención del doctorado, hemos podido comprobar que, aunque en las primeras décadas del siglo XX ya se había producido un fenómeno de valoración del patrimonio cultural de la localidad, no fue hasta la época de la dictadura franquista cuando se activó la conciencia que ha desembocado en el estado actual de dicha cuestión. Fue a partir de entonces cuando se abrió el camino a la realización de obras de restauración, científicamente entendidas, sobre su arquitectura histórica (Infante, 2012) y, con los trabajos de Juan Pedro Garrido y Elena Orta (Garrido; Orta, 1974: 25-26), a una serie de intervenciones arqueológicas que precedieron a las desarrolladas por la Universidad onubense en las últimas décadas.

El hecho de que aquella corriente -en la que desempeñó un papel crucial la prensa provincial- se produjese en el complejo contexto de la dictadura, hizo que se recurriese, de forma frecuente, a conceptos históricos muy vinculados con la ideología oficial promovida por el régimen. La heroicidad y todo lo relacionado con la guerra, por otra parte, fueron claves a la hora de establecer prioridades en una población que con la llegada del desarrollismo empezaba a asomarse a la modernidad, lo que también tuvo su repercusión en la valoración que se hizo del patrimonio. Por último, las oportunidades que comenzaban a verse en el turismo de masas fueron cruciales, igualmente, para establecer los criterios a seguir en este sentido.

Este artículo analizará todos estos factores, para tratar de determinar, a través del paradigmático ejemplo de esta pequeña y periférica localidad monumental, qué importancia tuvo para el Patrimonio Cultural el periodo surgido de la más dura contienda bélica que ha vivido este país. Nos hemos valido, para ello, del análisis de la prensa provincial del momento, especialmente del diario Odiel, así como de la documentación contenida en el Archivo Municipal de Niebla. Unas fuentes y otras nos han proporcionado la visión que, tanto a nivel social como a nivel político respectivamente, se tuvo del asunto. 


\section{La importancia de la historia en la legitimación del franquismo}

El hecho de que las bases del franquismo se hubiesen cimentado sobre una contienda bélica exigió al régimen una importante tarea de justificación y legitimación. De aquí que, en contraste con la miseria reinante, en la España de la autarquía gozase de especial protagonismo la intensa política de movilización de masas y de desarrollo de ceremonias públicas practicada por Falange y los círculos católicos (Casar; Esteban, 2008: 11)1. Esa misma herramienta ya se había utilizado durante los años de la guerra, en los que la prensa y las fiestas populares, ambas instrumentalizadas y dirigidas por los ideólogos del nuevo orden, se convirtieron en un medio realmente eficaz para transmitir la noción de que el Movimiento Nacional representaba la estabilidad, la paz y la recuperación de los auténticos valores de España, frente al caos que había generado la República (Cordero, 1997: 137-153). En este mismo sentido, resulta muy interesante el análisis que ha realizado Vicente Sánchez-Biosca (2008: 73-83) sobre la utilización de otro elemento destinado al mismo fin, la figura del Alcázar de Toledo, que resistió el asedio al que fue sometido por las fuerzas republicanas entre julio y septiembre de 1936, convirtiéndose en símbolo mitificado y sacralizado del franquismo. Después de aquel episodio se procedió a la construcción consciente, intencionada y meticulosa de toda una mitología alrededor del edificio y de la defensa numantina del mismo, con el deseo de disponer de un emblema que sirviese "de sustento espiritual a los miembros de la sociedad o grupo cuya cohesión se perseguía" (Sánchez-Biosca, 2008: 73).

El recurso a la Historia fue bastante solvente para sustentar y dar contenido a esa base ideológica que pretendía imponerse. La historiografía ha señalado con frecuencia que la cultura, durante la dictadura, fue un claro instrumento de legitimación y control (Alcover, 1977: 145-146), cuestión que ha sido matizada recientemente por historiadores como Enric Ucelay-Da Cal (2008: 17-19), que, a pesar de todo, no deja de apuntar que en el ámbito cultural de aquella España hubo una ideología dirigida y encaminada a imponer una noción mitificada de la nación. Dentro del ejercicio de cualquier actividad intelectual, se corría el riesgo de entrar en un terreno peligroso, dadas las connotaciones políticas que podía tener y las consecuencias que podía acarrear. Por lo tanto, no nos equivocaríamos al decir que en aquellos momentos, a nivel general, se hizo una utilización conscientemente partidista y parcial de la Historia. Así se refleja en el ya citado caso del Alcázar toledano, para cuya construcción simbólica se recurrió a buscar un entronque del edificio solo con los acontecimientos pretendidamente más brillantes de nuestro pasado (Sánchez-Biosca, 2008: 75-76). De igual modo, Rafael Valls (1986: 231-233) ha señalado que en lo referente a educación se le concedió a dicha materia un papel crucial para la socialización de la juventud y como elemento apologético del Estado. Pone como ejemplo la Ley de Reforma de la Segunda Enseñanza de 1938, en la que se expresaba que se debía promover la "revalorización de lo español" y la oposición al "pesimismo antihispánico y extranjerizante" contenidos en los valores de la República. 
De todo esto se deduce la importancia que adquirió durante la dictadura todo lo relacionado con la Historia de España, que, manipulada y con la intención de proceder a la depuración ideológica de la sociedad, llegó a transmitirse, de forma masiva, incluso a través de los medios de comunicación (Durán Froix, 2008: 33-45). En la provincia de Huelva, las páginas del diario Odiel, por ejemplo, aparecían cargadas de continuas referencias a acontecimientos del pasado, en un lugar potencialmente sensible a las glorias históricas, por su proximidad al tema del Descubrimiento, a nivel regional (Cordero, 1997: 138-144), y por el significativo papel político desempeñado, en determinados momentos, en el caso concreto de Niebla.

\section{Niebla y su historia durante el régimen}

En el contexto descrito, Niebla percibió que contaba con una serie de condicionantes que podrían otorgarle un enorme prestigio. Por este motivo, entre la década de 1940 y los años sesenta fue habitual la publicación de reportajes promocionales de la feria de Todos los Santos, las fiestas patronales o la Semana Santa en el citado diario Odiel, en los que, con la intención de transmitir que dichas celebraciones tenían un carácter especial, se recalcaba el fuerte sustrato histórico de la población. Así lo vemos en estas palabras alusivas a la feria de 1949, redactadas por Ramón Ortega Egurrola (1949: 4), el principal ideólogo del universo cultural iliplense de esta época ${ }^{2}$ :

Porque la feria de Niebla no es una feria cualquiera; ni siquiera una feria igual a las demás. Tiene un sello propio, inconfundible, de soberana realeza, que la hace elevarse por cima de la ordinaria realidad de una feria pueblerina: su empaque.

... una feria que por sí y para sí requiere el ambiente viril del recinto amurallado. Este factor de pobre elegancia es, precisamente, el que eleva el tono al conjunto de la feria y la hace parecer y ser, por rara paradoja, una feria de belleza recia sin igual.

Lógicamente, ante la situación descrita, el interés por la historia de la antigua Ilipla había comenzado a cuajar también a nivel institucional. A partir de estos años, el Ayuntamiento recurriría a diversos informes históricos que emplearía para la realización de diferentes gestiones municipales o, simplemente, para tener presente esa perspectiva que se había impuesto en lo político. Así, en 1958, por ejemplo, las autoridades locales adquirieron a la empresa madrileña Recopilaciones Históricas Hispania un estudio que, firmado por A. Vargas, compiló un amplio número de fuentes que en época moderna y en el siglo XIX habían hecho referencia a Niebla, bien desde un punto de vista geográfico, bien desde un punto de vista de su significación en tiempos pasados $^{3}$. De igual modo, en el informe Veinte años de paz en el Movimiento Nacional, bajo el mando de Franco, realizado en 1959 para mostrar, con motivo de tal efeméride, el estado en el que se encontraba el municipio en materia de infraestructuras, sociedad, vida religiosa, etc., se incluía un apartado titulado "Historia recompilada de la ciudad de Niebla”, en el que se hacía un repaso por los acontecimientos más prototípicos de la historia de la localidad ${ }^{4}$. Además, se conserva en el Archivo Municipal 
otro informe con el título Niebla en la Historia, realizado en los años sesenta por Ramón Ortega Egurrola ${ }^{5}$, director, por otra parte, de la revista Niebla Histórica, que comenzó a ser editada en estos momentos por el Consistorio con motivo de las fiestas patronales de la Virgen del Pino y en la que se entremezclaba la información local de tipo propagandístico y político con otra de carácter poético e histórico.

Todas estas referencias al pasado tenían en común una serie de connotaciones y características que, imbricadas en el contexto intelectual descrito, construirían una visión mitificada, interesada y, en definitiva, algo parcial de la historia de Niebla. Todas las interpretaciones hechas se ceñirían al modelo histórico impuesto por el franquismo, es decir, el modelo moral-católico que ya había sido apuntado en el siglo XVI (Wulff, 2003: 12-18). Éste se basaba en la idea de que el único defecto del primigenio pueblo español, la desunión, se había visto superado gracias a la acción unificadora del cristianismo. Los momentos más brillantes de nuestra historia, de este modo, habrían coincidido con aquellos periodos en los que la acción de los gobernantes se había caracterizado por la defensa de la doctrina católica, logrando, en consecuencia, la unidad de la nación. Así, el mundo visigodo, la Baja Edad Media -especialmente el reinado de los Reyes Católicos- y el periodo de los Austria se convirtieron en el paradigma de la auténtica España. Por contra, las etapas de mayor decadencia habrían coincidido con una carencia absoluta de la fe o una relajación de los valores derivados de la misma, lo que habría provocado la fragmentación de la esencia patria y sus territorios - dígase, por ejemplo, la dominación romana, el periodo islámico, el siglo XVIII con la influencia de la Ilustración, el siglo XIX con la introducción del liberalismo o, sin ir más lejos, la Segunda República-. El caso de la construcción de la historia de Niebla es paradigmático en este sentido, realizándose en base a una valoración positiva, por ejemplo, del periodo visigodo, momento en el que la ciudad se había convertido en sede episcopal, contado con una nómina de obispos que habían llegado a participar en los Concilios de Toledo (Odiel, 1955: 7). Pero el asunto más relevante no podía ser otro que la acción reconquistadora de Alfonso X el Sabio, mostrándose, por antagonismo, una visión negativa del periodo musulmán (Ortega, 1959b: 4), especialmente de todo lo relacionado con lo almohade, llegando a escribirse la siguiente afirmación:

...aquellos fosos donde la luz de la inteligencia quedó cegada por la insania de aquellos conquistadores almohades que trajeron con ellos la muerte con el sacrificio de ocho mil infantes iliplenses, por aquellos fieros guerreros que, no obstante, al acariciar sus corazones embotados por las arenas del desierto africano, la dulce ambrosía de nuestras tierras andaluzas, nos trajeron después cultura, arte, civilización en suma (Ortega, 1968: 429).

Como señala Alicia Alted Vigil (1986: 218-219), durante los años de la Guerra Civil se había producido una identificación absoluta de la religión como parte integrante de la tradición histórica nacional, apareciendo lo religioso y lo patriótico, desde entonces, "en la base de toda realización de política educativa y cultural". Precisamente, cualquier análisis que se hiciese de la historia iliplense quedaba revestido de un aire católico que relativizaba y convertía en vanidad aquel pasado glorioso. La verdadera 
grandeza de Niebla residía en que aquel devenir temporal, también cargado de fracasos, había quedado redimido por la enorme fe demostrada por el pueblo ${ }^{6}$.

Por otra parte, el tono épico y ensoñador, en el que la leyenda se confundía con la realidad, era otra de las características de cualquier narración que se hiciese entonces. En este sentido, es bastante significativa la utilización que se hizo de algunos temas tratados por el sacerdote Cristóbal Jurado en las primeras décadas del siglo $\mathrm{XX}^{7}$, llegando a emplearse sus trabajos como base, sobre todo, en relación con la aparición de la Virgen del Pino y la vida de San Walabonso, santos patronos de la localidad, o el episodio de un decurión romano oriundo de la misma, Fabato, que estuvo presente en el Gólgota durante la crucifixión de Cristo. Este último caso es especialmente significativo, puesto que trató de otorgársele un carácter científico que le diese veracidad ${ }^{8}$.

Por último, habría que hacer hincapié en que determinadas valoraciones y ponderaciones del papel político, comercial o social, así como de los hechos coyunturales que tuvieron lugar aquí en el pasado, se hacían empleando términos absolutos, otorgándoseles, en ocasiones, una importancia desmedida. Aquello era fruto de ligeras o inexistentes reflexiones, realizadas sin utilizar un correcto aparato crítico o con la mera intención, como ya hemos dicho, de magnificar el prestigio de la localidad y, por tanto, el de la nación. Son muy expresivas, a este respecto, las siguientes palabras de Juan Alcántara Sánchez (1956: 15):

No parece habérsele dado a la ciudad de Niebla la importancia histórica que tuvo en el pasado... Sin embargo, la proyección de su vida, estrechamente unida a la de sus gobernantes y moradores, a través del tiempo, nos hace ver hechos de destacado valor en la Historia.

Romero Delgado (1957: 10) iba más allá, al indicar que "Hablar de Niebla es siempre interesante. Si hablamos de su historia, su interés es universal". La misma línea seguía Ortega Egurrola cuando escribía que, con el informe Niebla en la Historia, había tratado de mostrar, brevemente, "su gran valía como avanzadilla de la civilización occidental", afirmación que trataba de acotar en otras ocasiones, intentando ceñirse a un contexto nacional y justificando que tal importancia residía, por ejemplo, en el hecho de que, según la Historia General de Alfonso X, hubiese sido el primer lugar de España en poblarse después de una larga sequía que había durado 26 años y otros acontecimientos semejantes (Ortega, 1959a: 9). Dicho autor, además, no tenía dudas acerca de que Niebla hubiese aparecido "en todos los grandes acontecimientos que se desenvolvieron en la Península" ${ }^{10}$, cosa que recalcaba también José María Segovia Azcárate en una conferencia organizada por el Ayuntamiento y la fábrica de Cementos del Sur, en la que se había referido "a la presencia histórica de la vieja Ilipla en las dominaciones fenicia, cartaginesa, romana, visigoda, árabe y cristiana" (Odiel, 1968: 5). Era frecuente encontrar en estos trabajos, por otra parte, intentos de equiparar la ciudad onubense con otras de gran significación para la Historia de España en el contexto de la ideología oficial del momento, como por ejemplo Toledo, Ávila o Córdoba (Odiel, 1955: 7; Ortega, 1967: 78 y 1969: 5). Por todo esto, no es de extrañar que en ocasiones se recurriera a comentar, sin cortapisa alguno, que se 
trataba de la localidad con mayor carácter histórico de la provincia o que era una de las poblaciones más antiguas de Andalucía (Odiel, 1941: 6 y 1954: 30).

\section{El turismo como motor de desarrollo y el creciente interés de Niebla}

La década de 1950 fue la de la recuperación económica definitiva de las potencias aliadas tras la Segunda Guerra Mundial, lo que favoreció la estabilidad de una clase media, surgida del contexto capitalista, para la que la salida al extranjero en busca de vacaciones se había convertido en una práctica habitual (Fernández, 1991). Al mismo tiempo, la relativa apertura hacia el exterior experimentada por el régimen franquista favoreció la integración de España en el contexto internacional. Los pactos de colaboración con los Estados Unidos y el ingreso en la Organización de Naciones Unidas, junto con otros hechos coyunturales, permitieron, de un modo u otro, cierta normalización en la vida del país mientras se producía, en paralelo, la institucionalización de la actividad turística (Uriel; Montfort, 2001: 17). Así, en 1951 se creaba el Ministerio de Información y Turismo, mientras que el Ministerio de la Presidencia, en 1952, lanzaba el llamado Plan Nacional de Turismo, en el que por primera vez se contemplaba dicho fenómeno de una forma global, entendiéndose que podía tener grandes repercusiones económicas (Esteve; Fuentes, 2000: 55-59). Sin embargo, hasta la puesta en marcha del Plan de Estabilización de 1959 no se producirá un auténtico desarrollo del sector, en base a la necesidad de la obtención de divisas y capital extranjero que garantizase el éxito de las reformas económicas iniciadas; en este sentido, el turismo se mostraba como la fuente de ingresos que podía propiciar el desarrollo de la nación y su modernización industrial. Esto coincidiría, además, con un notable incremento del número de visitantes extranjeros en los últimos años y con la llegada al Gobierno de Manuel Fraga, que en 1962 se haría cargo del Ministerio para proporcionarle un notable impulso a dicha parcela ${ }^{11}$.

Niebla ya había tenido sus primeras experiencias relacionadas con estas actividades en los años anteriores a la Guerra Civil, debidas a la iniciativa particular de Elena Whishaw ${ }^{12}$. En aquellos momentos, bajo la dirección ideológica de la Comisaría Regia y posterior Patronato Nacional de Turismo, el interés fundamental por dicho sector venía derivado, en buena medida, de la preocupación por conservar el Patrimonio Cultural español (Fernández, 1991: 280; Cal, 1997: 125-133). De un modo incipiente, la inglesa había entendido que las visitas culturales podían ser un modo eficiente de poner en valor el Patrimonio arquitectónico y arqueológico de la localidad y de atraer los fondos necesarios para llevar a cabo las pertinentes tareas de conservación y restauración (Acosta, 2006: 730). Buena parte de su actividad estuvo centrada en la promoción de sus trabajos arqueológicos y del Museo que instaló en la Puerta del Buey de la muralla, pero también de los Lugares Colombinos, aprovechando, sobre todo, la coyuntura de la Exposición Iberoamericana de Sevilla de $1929^{13}$. Sin embargo, aquel turismo no se parecía en nada al que va a comenzar a moverse en la época del boom del desarrollismo. Presentaba un corte selectivo y 
clasista, no sólo desde el punto de vista económico o social, sino también desde el punto de vista intelectual, lo que le otorgaba un carácter minoritario. Precisamente, este fue uno de los motivos por los que el sector no terminó de aparecer ante la sociedad como un elemento plenamente productivo, puesto que no generaba bienes físicos inmediatos (Esteve; Fuentes, 2000: 50).

En la localidad onubense, a raíz de la guerra y la muerte de la inglesa, la conciencia en torno a las ventajas que podían ofrecer iniciativas de aquel tipo entraría en un periodo de letargo. Hasta los años cincuenta, precisamente, no vuelve a apreciarse un tímido interés de las autoridades locales en el asunto, motivado por los movimientos que se comenzaban a dar en la Administración. De este modo, la corporación municipal acordaba, en 1956, la adquisición de una serie de fotografías "de los edificios y sitios más típicos de la Ciudad para efectos de turismo", puesto que la Oficina de Información y Turismo lo había solicitado formalmente unos días antes ${ }^{14}$. Otra medida de semejante carácter sería la adoptada tan sólo algunos meses más tarde. La Junta Provincial de Turismo había emitido una circular instando a los vecinos de Niebla a dispensar una buena acogida a los visitantes que acudieran a la misma, acordándose en pleno "tomar esta circular con agrado" y prestar "la debida cooperación"15. Y es que, a pesar de todo, es de suponer que el fuerte sustrato histórico y monumental de Niebla, así como el eco que habían alcanzado en su momento los trabajos de Elena Whishaw, habían seguido atrayendo visitas foráneas, sobre todo si tenemos en cuenta que la localidad se había integrado en la llamada "Ruta Colombina", con la que pretendía promocionarse el turismo en el entorno de La Rábida.

Con todos estos antecedentes no es de extrañar que en determinados sectores de la sociedad iliplense, ya a finales de la década y, sobre todo, en los años sesenta, comenzase a percibirse que Niebla tenía ante sí una oportunidad inigualable para iniciar un proceso de desarrollo que la sacase del estancamiento en el que había estado sumida en los últimos siglos y le permitiese subir al tren de la modernización que parecía haber tomado el país. El turismo aparecía ante los ojos de los españoles como un auténtico motor capaz de generar riqueza y bienestar social, y aquel punto de la geografía onubense, a juicio de la opinión pública local, contaba con todos los ingredientes para convertirse en un auténtico referente en tal sentido: una tradición histórica que se estaba revalorizando, importantes muestras arquitectónicas y arqueológicas de aquel pasado y cierto renombre y tradición turística heredados de la época prebélica. Todo esto se veía favorecido, además, por una situación geográfica privilegiada y propicia para la atracción de grandes flujos de visitantes, puesto que la localidad se encontraba en plena Ruta Colombina y a mitad de camino entre la costa, la sierra y Sevilla (Odiel, 1966a: 3; González, 1965: 4). Así aludía Ortega Egurrola (1958: 16), refiriéndose a una subvención que se había otorgado para obras de restauración en la muralla, al carácter preponderante que, en lo turístico, podía tener la localidad dentro del contexto provincial:

Poco, muy poco dinero para la obra que hay que realizar si queremos dignamente hacer de nuestras murallas y Museo, dentro de la ruta Colombina, uno de los puntos más interesantes que pueda visitar el turista... confiamos, no obstante, que percatán- 
dose todos de que la conservación de las murallas milenarias y del Museo Arqueológico es una de las principales e interesantes cosas de nuestra provincia, que siempre han llamado la atención del turismo en general, se trabajará con ahínco para lograr que esta suma se centuplique para dar al recinto amurallado de Niebla el mismo tono que presentan las murallas gloriosas de Córdoba.

Lógicamente, ante esta conciencia creciente, el turismo terminó por convertirse en un asunto de cierta prioridad para el Ayuntamiento. El propio Alcalde, Manuel Molina, mostraba en una entrevista concedida a Odiel en 1958 el interés del consistorio en llevar a cabo ciertas obras, motivadas por el deseo de fomentar dicha actividad en la población:

-¿Nuevas obras?

-Sí. Se viene trabajando en la pavimentación y alcantarillado de la Puerta del Socorro y Puerta de San Martín, consideradas hoy como la entrada principal a la ciudad, y tenemos en proyecto la pavimentación y alcantarillado de la plaza de Santa María, la que en un futuro próximo se verá convertida en un hermoso lugar ya que figura en la ruta colombina (Montero, 1958: 14).

\section{Primeros beneficios y mayor compromiso con la actividad turística}

La mayor atención gubernamental al sector a partir de la llegada de Fraga Iribarne al Ministerio, en 1962, propició un sorprendente crecimiento del mismo. Ahora, los beneficios de esta actividad se harían más evidentes y resultarían más inmediatos. En 1963 se aprobaba la Orden de 28 de junio sobre concesión de créditos a las corporaciones locales radicadas en zonas turísticas, por la que los Ayuntamientos afectados gozaban de facilidades para solicitar un crédito al Banco de Crédito Local, destinado a realizar reformas de urbanización, tales como las de abastecimiento de aguas, alcantarillado, pavimentación, etc. (Esteve; Fuentes, 2000: 117-118). El consistorio tomaba conciencia de estas ventajas en septiembre de dicho año ${ }^{16}$, aunque hasta marzo de 1965 no se concretaba una iniciativa municipal orientada al aprovechamiento de los beneficios que ofrecía la norma:

El Señor Alcalde expone a los Señores asistentes, que tanto para él como para el pueblo en general, constituye un vehemente deseo la necesidad perentoria de procederse a la urbanización, aunque sea parcialmente, de la población, mediante nueva pavimentación y alcantarillado de las vías más céntricas y otras que conducen a los lugares artísticos-históricos con que cuenta la población, con lo que se conseguiría mejorar notablemente la fisonomía de la ciudad, haciendo desaparecer el pavimento de tierra y guijarros de la mayor parte de sus vías urbanas, con lo que se contribuiría a la higiene y sanidad del vecindario y presentaría mejor aspecto a los numerosos turistas que se desplazan para visitar nuestro recinto amurallado ${ }^{17}$.

En concreto, se planteó la pavimentación y alcantarillado de las plazas de Santa María y Generalísimo Franco - actual Plaza de La Feria-, así como de una serie de calles del centro de la población y de las puertas del Agua y del Buey, aunque en este 
último caso sólo era necesario arreglar la solería. También se pretendía la ampliación de la red de abastecimiento de agua y la conclusión de la nueva casa consistorial. La moción fue aprobada por unanimidad, acordándose, además, solicitar ayuda técnica gratuita a la Diputación Provincial para el estudio y la redacción de los proyectos correspondientes. Pasarían dos años hasta que la Dirección General de Promoción del Turismo anunciase que el Banco de Crédito Local había concedido tres millones de pesetas al Ayuntamiento de Niebla para la realización de las obras (Odiel, 1967: 4). Unos meses más tarde, el pleno municipal aprobaba el proyecto de contrato que se establecería entre ambas entidades para la formalización del crédito, especificándose que se concedía en virtud de la orden de 28 de junio de 1963 antes citada y que las cantidades eran, exactamente, de un millón de pesetas para obras de alcantarillado y de dos millones más para las de ampliación de la red de abastecimiento de aguas ${ }^{18}$. Estas obras se realizaron a lo largo de los años sucesivos, haciéndose tangibles, de este modo, los beneficios de la apuesta por el turismo.

Este fue el motivo que llevó a los ediles a adquirir ese importante compromiso con el fomento de dicha actividad ${ }^{19}$, compromiso que ya, de todas formas, había quedado patente unos años antes. Dentro de las medidas de promoción impulsadas por el Ministerio, en 1964 se había celebrado la I Asamblea Nacional de Turismo, precedida de otras asambleas de carácter provincial (Fernández, 1991: 834). La I Asamblea Provincial de Huelva tuvo lugar durante los días 21, 22 y 23 de enero de 1964 (Ortega, 1966a: 2), dentro de un ambiente de optimismo generado por la noticia de que España había accedido al segundo puesto del ranking mundial de visitantes recibidos, lo que suponía, en palabras del Director General de Promoción del Turismo, unos ingresos de 525 millones de dólares (Odiel, 1963b: 1). Niebla, como no podía ser de otro modo, había participado en este foro, en el que se habían analizado los principales problemas del sector provincial, planteándose sus posibles soluciones y una serie de medidas destinadas a su mejora. En las conclusiones obtenidas del encuentro se reflejaron ampliamente las necesidades del municipio. Así, el punto XII, que estaba dedicado a "Monumentos artísticos e históricos", señalaba, en su segundo apartado, lo siguiente:

Deben ser aumentados los trabajos de reconstrucción y conservación de las murallas de Niebla.

Hacer desaparecer las construcciones más o menos clandestinas, que se han hecho adosadas a la muralla utilizando parte de su castillo, así como aquellas que le quitan visibilidad.

Hacer efectiva una zona de seguridad alrededor de las Murallas, hermoseada con jardines en las que no se permita edificar, completada con iluminaciones indirectas de estas Murallas (Ortega, 1966a).

El sexto apartado, por otra parte, reflejaba que debían "vitalizarse los museos Municipales situados en las comarcas arqueológicas más ricas como las de Niebla y Aroche, cuyas colecciones pueden ser fácilmente ampliadas, no solamente con los hallazgos fortuitos sino con pequeñas campañas de excavaciones" (Ortega, 1966b: 
2). A estas conclusiones habría que sumar las de la II Asamblea y las de la I Asamblea Provincial de Municipios Turísticos, ambas celebradas en noviembre de 1967 (Ortega, 1968: 430-431), en las que se acordaron una serie de puntos que incidían e insistían en los mismos aspectos ya expuestos.

Precisamente, en relación con la Asamblea de Municipios Turísticos, se conserva en el Archivo Municipal una ponencia titulada Conservación y revalorización del patrimonio artístico monumental de los municipios, leída por el alcalde Manuel Molina García en una de las reuniones preparatorias, celebrada en Niebla el 8 de junio del mismo año ${ }^{20}$. En ella, el ponente hacía una valoración de la importancia del Patrimonio arquitectónico y arqueológico iliplense y el de toda la provincia, repasando su estado de conservación y las necesidades y proyectos que el municipio tenía en este sentido. De esta forma, trataba de poner de relieve que "el Patrimonio Artístico y Monumental" constituía "un atractivo para el turismo, quizás el más grande,... por lo que entre otras razones de mayor valor, debe cuidársele y conservarle con todo esmero". En las conclusiones de la exposición aparecían una serie de puntos a acordar por los participantes, destinados a fomentar una mejor y más eficaz gestión del Patrimonio, bajo el convencimiento implícito de que así se produciría una mejora evidente del sector turístico.

\section{Conclusiones}

Dentro del ambiente ideológico, político y social descrito, es perfectamente comprensible que la arquitectura histórica de Niebla comenzase a adquirir un valor del que prácticamente había carecido hasta entonces. Se cumplió a la perfección aquello que señala Javier Rivera Blanco (2008: 94-96), cuando alude a que los monumentos nacionales, durante el régimen, aparecieron como elementos cargados de una fuerte significación ideológica y política, aglutinando los valores más profundos de la esencia del país. La muralla de Niebla, el Alcázar o las iglesias de Santa María y San Martín eran ahora los restos materiales y simbólicos de esa historia mitificada y engrandecedora que se había construido ${ }^{21}$. De paso, este patrimonio se constituyó en una base fundamental para el desarrollo de las iniciativas turísticas, lo que a su vez exigía una correcta gestión del mismo. Esta idea se mantuvo presente en el imaginario colectivo a lo largo de las siguientes décadas, gracias, entre otras cosas, a que la prensa recurrió a expresar frecuentemente la importancia de una correcta conservación de los monumentos de Niebla en función de las necesidades turísticas de la localidad (Romero, 1958: 14; Odiel, 1966b: 6). Esto cimentó la conciencia de que era necesario, de una vez por todas, llevar a cabo una política efectiva en lo que a conservación y restauración del patrimonio arquitectónico iliplense se refería. (Gráfico 1) 


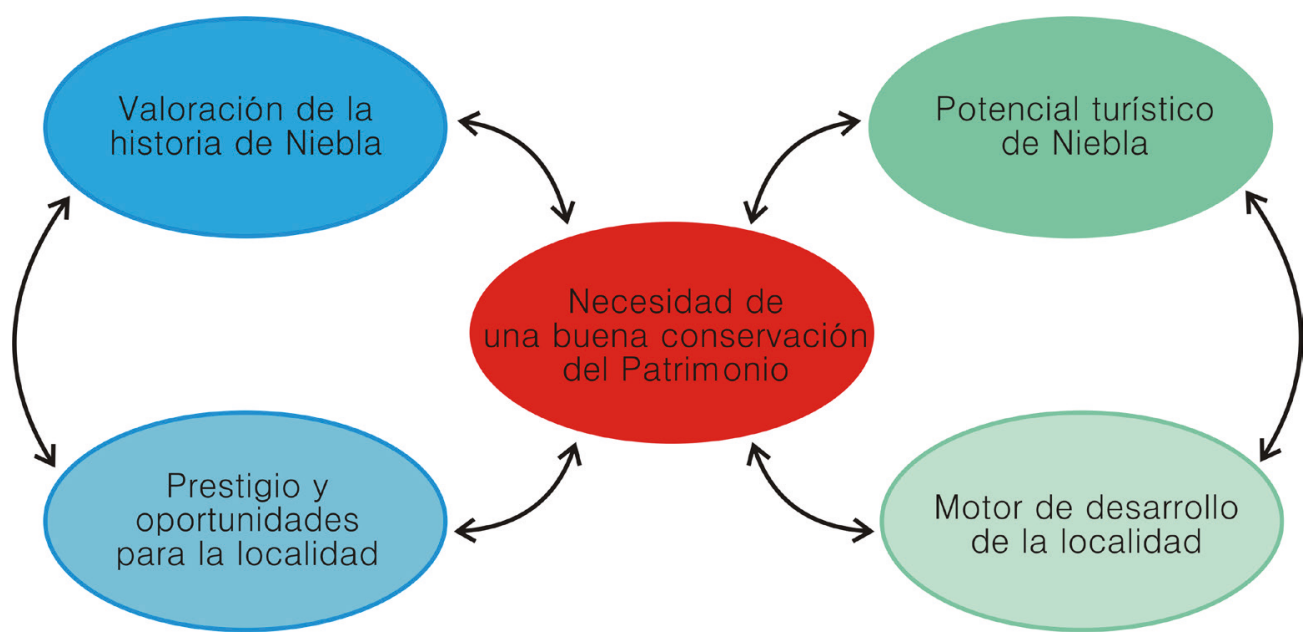

Gráfico 1

Como hemos podido ver a lo largo del artículo, el elemento que concentró la mayor atención de la sociedad y de las esferas políticas en este sentido fue el recinto fortificado, quizás, en parte, por su carácter definidor para la población y, sobre todo, porque había sido revalorizado con la declaración de Monumento Histórico-Artístico que había recibido en $1945^{22}$. Aunque aquel reconocimiento se anticipó unos años al decreto de 1949 para la protección genérica de los castillos españoles, podemos entender que ambas medidas surgieron de la misma motivación. En aquella España de propaganda y mitificación de los valores defendidos por el régimen, había alcanzado un reconocido prestigio la cuestión bélica, vinculada intencionadamente con valores como el honor o la heroicidad épica. La exposición de motivos de la declaración recalcaba la importancia histórica de la población, a la cual iba "unida como indeleble testimonio la ingente, bien que arruinada y desfigurada, obra de fortificación en la que dejaron su huella, con sus distintos sistemas de construcción, las sucesivas épocas". De este modo, además de su mal estado de conservación y del hecho de que era testigo material de casi todas las fases de ocupación desde la época romana, en la base de la valoración que se hacía de la cerca defensiva estaba implícito ese componente de prestigio que ofrecía un pasado rico en matices bélicos y, por tanto, heroico. La sociedad local, a lo largo de aquellos años, le otorgó a la muralla y al alcázar, en consecuencia, un carácter preponderante por encima de otros testimonios arquitectónicos y arqueológicos, lo que viene a poner de relieve el calado que tuvieron estas cuestiones, a pesar del carácter marcadamente confesional del régimen, en la España franquista.

Sobre un alcor pletórico de gloriosas epopeyas se asienta la ciudad de Niebla... mirando siempre hacia Oriente, sus puertas se abren libremente cantando épicos romances, gritando angustias de heroísmos, señalando ruinosas muestras de ascendencia de todas las épocas que aquí, en citas permanentes de guerras, sucumbieron o triunfaron, gozaron o sufrieron, vivieron o murieron... 
Niebla, la que puede denominarse la Ávila del Sur de España, porque mantiene, a pesar del abandono en que se le ha tenido, todo su recinto completo, con sus tres mil metros de murallas duras pétreas como cíclopes terrosos que dominan inconmovibles todo el antiguo Axarafe, se encuentra desde hace unos años sujeta a la reconstrucción de sus monumentos nacionales... (Ortega, 1967: 77-78).

\section{Referencias bibliográficas}

ACOSTA FERRERO, J. M. (2003). Elena Whishaw: Entre la leyenda y la realidad. Huelva: Diputación Provincial de Huelva.

(2006). Elena Whishaw y Niebla: la dama de las piedras. Tesis doctoral, Universidad de Huelva.

(2012). Elena Whishaw, 75 años después. Madrid: Cultiva Libros.

ALCÁNTARA SÁNCHEZ, J. (1956). "Breve historia de la Niebla musulmana". En Odiel, 28-10-1956.

ALCOVER, N. (ed.) (1977). La cultura española durante el franquismo. Bilbao: Mensajero.

ALTED VIGIL, A. (1986). "Notas para la configuración y el análisis de la política cultural del franquismo en sus comienzos: la labor del Ministerio de Educación Nacional durante la Guerra". En FONTANA, J. (ed.) (1986). España bajo el franquismo. Barcelona: Crítica, pp. 215-229.

CAL MARTÍNEZ, R. (1997). "La propaganda del turismo en España: Primeras organizaciones". En Historia y comunicación social, $\mathrm{n}^{\circ}$ 2, Madrid: Universidad Complutense de Madrid, pp. 125-134.

CAMPOS, J. M.; GÓMEZ, F.; PÉREZ, J. A. Ilipla-Niebla. Evolución urbana y ocupación del territorio. Huelva: Universidad de Huelva.

CAMPOS, J.; RODRIGO, J. M.; GÓMEZ, F. (1996). Arqueología urbana en el conjunto histórico de Niebla (Huelva); Carta del riesgo. Sevilla: Junta de Andalucía.

CASAR PINAZO, J. I.; ESTEBAN CHAPAPRÍA, J. (eds.) (2008). Bajo el signo de la victoria. La conservación del patrimonio durante el primer franquismo. Valencia: Pentagraf.

CORDERO OLIVERO, I. (1997). "Huelva durante la guerra civil: las celebraciones públicas". En: Huelva en su Historia, n 6, Huelva: Universidad de Huelva, pp. 137-153.

DURÁN FROIX, J-S. (2008). “Televisión contra memoria. Uso y abuso de la Historia en la televisión franquista". En Historia y comunicación social, nº 13, Madrid: Universidad Complutense de Madrid, pp. 33-45.

ESPINOSA MAESTRE, F. (1996). La Guerra Civil en Huelva. Huelva: Diputación Provincial de Huelva.

ESTEVE SECALL, R.; FUENTES GARCÍA, R. (2000). Economía, historia e instituciones del turismo en España. Madrid: Pirámide. 
FERNÁNDEZ FÚSTER, L. (1991). Historia general del turismo de masas. Madrid: Alianza.

GARRIDO ROIZ, J. P.; ORTA GARCÍA, E. M. (1974). "Historia de la investigación arqueológica de la provincia de Huelva". En ALMAGRO BASCH, M. (et al.) (1974). Huelva: Prehistoria y Antigüedad. Madrid: Editoria Nacional, pp. 15-26.

GONZÁLEZ JIMÉNEZ, M. (1965). "Niebla y sus murallas". En Odiel, 12-5-1965.

INFANTE LIMÓN, E. (2012). "La muralla de Niebla entre el franquismo y la democracia. Intervenciones y restauraciones". En Cuadernos de Arquitectura y Fortificación, $n^{\circ}$ 0, Madrid: La Ergástula, pp. 153-196.

JIMÉNEZ MARTÍN, A. (1980). Huelva Monumental. Huelva: Delegación Provincial del Ministerio de Cultura.

JURADO CARRILLO, C. (1934). Mosaico de leyendas, tradiciones y recuerdos históricos de la ciudad de Niebla (Huelva). Lleida: Imprenta Mariana.

(1935). Mosaico de apuntes históricos de la ciudad de Niebla para uso de las escuelas, dedicados al pueblo de Niebla (Segunda parte). Lleida: Imprenta Mariana.

(1936). Mosaico o compendio breve de la historia de la ciudad de Niebla (Huelva) para los Alumnos de la Escuela de adultos (Tercera parte). Lleida: Imprenta Mariana.

LEMUS LÓPEZ, E. (1998). "Andalucía bajo el Franquismo". En ÁLVAREZ REY, L.; LEMUS LÓPEZ, E. (eds.) (1998). Historia de Andalucía Contemporánea. Huelva: Universidad de Huelva, pp. 457-495.

MONTERO, F. (1958). "Importantes reformas en la vieja ciudad de Niebla". En Odiel, 29-10-1958.

MORENO ORTIGOSA, F. (1962). "Un hijo de Niebla, testigo del drama de Cristo". En Odiel, 17-4-1962.

Odiel (1941), "Gran Feria de Ganados en Niebla", 31-10-1941.

(1954), "Niebla, la antigua Ilipla", 15-3-1954.

(1955),"Niebla recibe jubilosamente al Obispo", 27-4-1955.

(1956), "Presencia de Niebla en el Gólgota", 25-3-1956.

(1963a), "Un apeadero en la puerta del Buey", 13-3-1963.

(1963b), "España, segunda potencia turística", 2-7-1963.

(1965a), "Se constituye en Niebla la Comisión Pro-Monumentos Históricos y Artísticos de la ciudad de Niebla", 24-2-1965.

(1965b), "Niebla se encontró a sí misma en la maravillosa noche del 19 de septiembre", 22-9-1965.

(1966a), "Continuación de trabajos en las murallas", 17-2-1966.

(1966b), "Entronización y bendición de una Imagen de la Virgen del Pilar en la Casa Cuartel de la Guardia Civil", 22-5-1966.

(1967), "Tres millones de pesetas para el desarrollo turístico de Niebla", 9-3-1967. (1968), "Conferencia sobre historia en Niebla", 28-6-1968.

ORTEGA EGURROLA, R. (1949). "La feria a vuela pluma”. En Odiel, 30-10-1949. 
(1958). "Reconstrucción de las Murallas y Museo Arqueológico de Niebla. Hasta la fecha han sido concedidas ciento sesenta mil pesetas, por el Ministerio de Educación Nacional”. En Odiel, 2-12-1958.

(1959a). "Origen de la ciudad de Niebla". En Odiel, 15-2-1959.

(1959b). "Origen de la ciudad de Niebla. El sitio de Niebla, por el Rey Alfonso X el Sabio". En Odiel, 24-3-1959.

(1966a). "El castillo de los condes de Niebla se remoza (V). Mirada retrospectiva a unas conclusiones interesantes". En Odiel, 25-2-1966.

(1966b). "En defensa de nuestro acervo histórico, artístico y arqueológico. El Museo de Niebla, inexplicablemente expoliado". En Odiel, 22-5-1966.

(1967). "La reconstrucción de la monumental Niebla, en vías de realidad". En Castillos de España. Boletín de la Asociación Española de Amigos de los Castillos, $\mathrm{n}^{\circ}$ 56, Madrid: Asociación Española de Amigos de los Castillos, pp. 77-79.

(1968). "Niebla y sus piedras. El castillo roto". En Castillos de España. Boletín de la Asociación Española Amigos de los Castillos, n 63, Madrid: Asociación Española de Amigos de los Castillos, pp. 427-431.

(1969). "Córdoba ha dado el nombre de Niebla a una de sus calles". En Odiel, $1-5-1969$.

RIVERA BLANCO, J. (2008). “Consideración y fortuna del patrimonio tras la guerra civil: destrucción y reconstrucción del patrimonio histórico (1936-1956). La restauración monumental". En CASAR PINAZO, J. I.; ESTEBAN CHAPAPRÍA, J. (eds.) (2008). Bajo el signo de la victoria. La conservación del patrimonio durante el primer franquismo. Valencia: Pentagraf, pp. 85-110.

ROMERO DELGADO, J. (1957). "Resurgir de Niebla". En Odiel, 29-10-1957. (1958). "La Feria del Arte". En Odiel, 29-10-1958.

SÁNCHEZ-BIOSCA, V. (2008). "Arquitectura, lugar de memoria y mito. El Alcázar de Toledo o la imagen prendida". En CASAR PINAZO, J. I.; ESTEBAN CHAPAPRÍA, J. (eds.) (2008). Bajo el signo de la victoria. La conservación del patrimonio durante el primer franquismo. Valencia: Pentagraf pp. 71-84.

UCELAY-DA CAL, E. (2008). "Cultura y sociedad en el primer franquismo". En CASAR PINAZO, J. I.; ESTEBAN CHAPAPRÍA, J. (eds.) (2008). Bajo el signo de la victoria. La conservación del patrimonio durante el primer franquismo. Valencia: Pentagraf, pp. 15-20.

URIEL JIMÉNEZ, E.; MONFORT MIR, V. M. (dir.) (2001). El sector turístico en España. Alicante: Caja de Ahorros del Mediterráneo.

VALLS, R. (1986). "Ideología franquista y enseñanza de la historia en España, 19381953”. En FONTANA, J. (ed.) (1986). España bajo el franquismo. Barcelona: Crítica, pp. 230-245.

WULFF ALONSO, F. (2003). "Los antecedentes (y algunos consecuentes) de la imagen franquista de la Antigüedad". En WULFF ALONSO, F.; ÁLVAREZ MARTÍ-AGUILAR, M. (2003). Antigüedad y franquismo (1936-1975). Málaga: Centro de Ediciones de la Diputación de Málaga, pp. 9-32. 


\section{Notas}

1 Encarnación Lemus (1998: 471) coincide en señalar la misma cuestión, destacando el papel que jugó la prensa gráfica en la tergiversación de la imagen de la realidad social española, así como el de las ceremonias públicas, que enmascaraban la auténtica situación, funcionando como "un ritual de manipulación emocional" que favorecía "la mitificación" de la imagen del régimen.

2 Ramón Ortega Egurrola desarrolló su actividad profesional en el área de administración de Bodegas Toro de La Palma del Condado (Huelva), ejerciendo, al mismo tiempo, como Secretario del Juzgado de Paz de Niebla. Francisco Espinosa Maestre (1996: 129) dice de él que fue concejal de dicha localidad durante los días del Frente Popular y Vicepresidente del Comité Ejecutivo Provincial de Unión Republicana, siendo el principal colaborador del alcalde Francisco Maya en las tareas de mantenimiento del orden en la localidad durante los días del Alzamiento. Sin embargo, no sabemos si puede tratarse de un error, puesto que en la documentación municipal aparece, como edil, Tomás Ortega Egurrola, tal vez familiar suyo. Ya durante el Régimen, Ortega sería habitual colaborador de Odiel, actuando como corresponsal de dicho diario en Niebla, de la que fue, igualmente, cronista oficial. Su labor periodística y literaria fue muy abundante, tratando, sobre todo, los temas relacionados con la historia de Niebla y sus monumentos. Sus artículos aparecieron en el citado medio casi a diario entre las décadas de 1940 y 1980, colaborando además, de forma circunstancial, en ABC, el Boletín de la Asociación Española de Amigos de los Castillos o la Revista de Festejos de La Palma del Condado. Recibió el Diploma de Honor de la Asociación Española de Amigos de los Castillos en 1967 ("Galardones concedidos por la AEAC desde 1958". [en línea]. [consulta: 8 de febrero de 2001] <http:// www.castillosasociacion.es/Galardones.htm>), por su implicación personal en la campaña para la conservación y restauración del Alcázar de los Guzmanes y el recinto amurallado (Archivo Municipal de Niebla -en adelante AMN-. Sección Ayuntamiento Pleno, Libro de Actas de la Comisión Municipal Permanente, 1959-1969, legajo 33, acta del día 12 de abril de 1967). Esta misma labor le valió para ser designado Consejero Local de Bellas Artes por el Ministerio de Educación y Ciencia en 1971 (Ibid. Libro de Actas de la Comisión Municipal Permanente, 1969-1977, legajo 34, acta del día 26 de mayo de 1971). Además, fue Secretario de la Comisión Pro-Monumentos Históricos y Artísticos de la localidad, constituida por el Ayuntamiento en febrero de 1965 (Odiel, 1965a: 7), y colaborador habitual del consistorio presidido por Manuel Molina García, no ya solo en este asunto, sino en otros de diversa índole.

3 AMN. Sección Ayuntamiento Pleno, Libro de Actas de la Comisión Municipal Permanente, 19461959, legajo 32, Acta del día 10 de diciembre de 1958. El informe se conserva, igualmente en el AMN. Sección Archivo, legajo 212, "Recopilación histórica de la Villa de Niebla. Por A. Vargas. Año $1958 "$.

4 Ibid. Sección Archivo, legajo 212, Veinte años de paz en el Movimiento Nacional, bajo el mando de Franco.

\section{Ibid. Niebla en la historia.}

6 En este sentido se expresaba José María Segovia Azcárate en el primer pregón de la Virgen del Pino, pronunciado en septiembre de 1965. De dicho discurso entresacamos un fragmento que, según entendemos, es bastante aclaratorio de dicha idea:

Fácil sería daros una charla de historia, aquí... entre estas viejas murallas que tanto saben de amor y de sangre, de luchas y de victorias, de fracasos y de muerte, de fe y de injurias. Pero no, Ella, vuestra Virgen ha querido que yo venga a Niebla... a silenciar la grandeza de su historia, a poner sello de humildad en las glorias pasadas... (Odiel, 1965b: 3). 
7 Cristóbal R. Jurado Carrillo (1867-1936) fue el párroco de Niebla desde 1889 hasta el final de sus días. Erudito preocupado por la Historia y la Arqueología, escribió tres libritos sobre Niebla que trataban temas relacionados con estas disciplinas y con narraciones de carácter legendario (Jurado, 1934, 1935, 1936).

8 Supuestamente, en el Archivo Municipal se conservaba una carta, transcrita al castellano por el escribano público Jerónimo de la Fuente en el siglo XIX, en la que Clodio Fabato, decurión iliplense destinado en Jerusalén, narra a su compañera sentimental, Iulia Marcela, la Pasión de Cristo, de la que había sido testigo. Al parecer, el documento había sido recogido por José María Trujillo de Vargas, que lo había publicado en "periódicos y revistas católicas" (Odiel, 1956: 16). Después se puso de relieve, en base a un artículo publicado en el semanario Domingo, firmado por Cecilio Barberán, que el municipio había regalado el documento, en 1869, a Emilio Castelar, desconociéndose su paradero (Moreno, 1962: 13). La prueba de que la leyenda tomó visos de realidad histórica la encontramos en una carta que remitía Juan Ponce Haldón al secretario del Ayuntamiento de Niebla en 1979, exponiéndole que había asistido a la Clausura del $35^{\circ}$ Cursillo de Cristiandad en Guadalajara, en la que había surgido el tema, motivo por el que solicitaba información acerca del paradero de la carta original (AMN. Sección Archivo, legajo 212, carta de 7 de septiembre de 1979 de Juan Ponce Haldón al Secretario del Ayuntamiento de Niebla).

9 AMN. Ibid. Niebla en la historia.

$10 \mathrm{Ibid}$.

11 Fernández Fuester (1991: 830-846) realiza un profundo análisis de esta etapa, que supuso una revolución para el turismo español. Señala que el gran impulso que se dio al sector desde el Ministerio se basó en una triple labor: la de adopción de una serie de medidas de ordenación, otras de promoción y la de creación de organismos complementarios, como la Comisión Interministerial de Turismo o el Instituto de Estudios Turísticos.

12 Elena Whishaw (1857-1937) fue una dama aristocrática de origen inglés que vivió en Niebla desde 1916 hasta su fallecimiento, llevando a cabo una intensa actividad cultural y arqueológica en la localidad (Acosta, 2003 y 2012).

13 En este periodo, la inglesa llegó a publicar dos obritas en las que se advierte, claramente, su interés por promocionar el turismo en la zona: Memoria con guía de los lugares Colombinos y Notas sobre el Puerto de Palos y las basílicas de San Jorge de Palos y Santa María de Niebla, ambas de 1927.

14 AMN. Sección Ayuntamiento Pleno, Libro de Actas de la Comisión Municipal Permanente, 19461959, legajo 32, acta del día 11 de febrero de 1956; y Libro de Actas Capitulares, 1949-1967, legajo 27, acta capitular del día 3 de marzo de 1956.

15 Ibid. Acta capitular del día 31 de julio de 1956.

16 Ibid. Acta capitular del día 30 de septiembre de 1963.

17 Ibid. Acta capitular del día 31 de marzo de 1965.

18 Ibid. Acta capitular del día 26 de mayo de 1967.

19 Otro ejemplo de este compromiso son las gestiones que desde 1965 realizaría el Ayuntamiento para que Renfe construyera un apeadero junto a la Puerta del Buey que viniera a paliar las deficiencias que ofrecía la estación de Las Mallas, excesivamente alejada del núcleo urbano. El objetivo era facilitar a los posibles viajeros la llegada en tren hasta la localidad (Odiel, 1963a: 4).

20 AMN. Sección Archivo, Reuniones previas a la I Asamblea de Municipios Turísticos de la Provincia de Huelva, Ponencia de D. Manual Molina García, Alcalde de Niebla: "Conservación y revalorización del patrimonio artístico y monumental de los municipios”, legajo 212. 
21 Así vienen a demostrarlo estas palabras de Juan Alcántara (1956: 15), aparecidas en Odiel: "De aquel esplendor, hoy sólo quedan murallas derruidas como muda elocuencia de pasadas grandezas".

22 La declaración se efectuó por decreto de 14 de abril de 1945 (Boletín Oficial del Estado, n ${ }^{\circ}$ 110, 20 de abril de 1945).

\section{El autor}

Enrique Infante es Licenciado en Historia del Arte, Máster en Arquitectura y Patrimonio Histórico y Especialista en Arqueología de la Arquitectura. Actualmente prepara su tesis doctoral en la Universidad de Sevilla, que lleva por título "Niebla cristiana. Arquitectura religiosa y urbanismo (1262-1525)". A nivel profesional ha estado vinculado con el Instituto Andaluz del Patrimonio Histórico y la Dirección General de Bellas Artes de la Secretaría de Estado de Cultura. Esta dedicación al Patrimonio Cultural se ha visto plasmada en la publicación de distintos trabajos que, en revistas como Laboratorio de Arte, Arqueología y Territorio Medieval o Cuadernos de Arquitectura y Fortificación, han tratado sobre la percepción que se ha tenido del mismo en distintos momentos históricos. 